\title{
Delirium in the geriatric unit: proton-pump inhibitors and other risk factors
}

This article was published in the following Dove Press journal:

Clinical Interventions in Aging

4 April 2016

Number of times this article has been viewed

\section{Iwona Otremba \\ Krzysztof Wilczyński \\ Jan Szewieczek}

Department of Geriatrics, School of Health Sciences in Katowice, Medical University of Silesia, Katowice, Poland
Correspondence: Jan Szewieczek

Department of Geriatrics, GCM, ul

Ziolowa 45/47, 40-635, Katowice, Poland

$\mathrm{Tel}+48323598239$

Fax +4832 2059483

Email jszewieczek@sum.edu.pl
Background: Delirium remains a major nosocomial complication of hospitalized elderly. Predictive models for delirium may be useful for identification of high-risk patients for implementation of preventive strategies.

Objective: Evaluate specific factors for development of delirium in a geriatric ward setting. Methods: Prospective cross-sectional study comprised 675 consecutive patients aged $79.2 \pm 7.7$ years ( $66 \%$ women and $34 \%$ men), admitted to the subacute geriatric ward of a multiprofile university hospital after exclusion of 113 patients treated with antipsychotic medication because of behavioral disorders before admission. Comprehensive geriatric assessments including a structured interview, physical examination, geriatric functional assessment, blood sampling, ECG, abdominal ultrasound, chest X-ray, Confusion Assessment Method for diagnosis of delirium, Delirium-O-Meter to assess delirium severity, Richmond Agitation-Sedation Scale to assess sedation or agitation, visual analog scale and Doloplus-2 scale to assess pain level were performed.

Results: Multivariate logistic regression analysis revealed five independent factors associated with development of delirium in geriatric inpatients: transfer between hospital wards (odds ratio $[\mathrm{OR}]=2.78$; confidence interval $[\mathrm{CI}]=1.54-5.01 ; P=0.001)$, preexisting dementia $(\mathrm{OR}=2.29$; $\mathrm{CI}=1.44-3.65 ; P<0.001)$, previous delirium incidents $(\mathrm{OR}=2.23 ; \mathrm{CI}=1.47-3.38 ; P<0.001)$, previous fall incidents $(\mathrm{OR}=1.76 ; \mathrm{CI}=1.17-2.64 ; P=0.006)$, and use of proton-pump inhibitors $(\mathrm{OR}=1.67 ; \mathrm{CI}=1.11-2.53 ; P=0.014)$.

Conclusion: Transfer between hospital wards, preexisting dementia, previous delirium incidents, previous fall incidents, and use of proton-pump inhibitors are predictive of development of delirium in the geriatric inpatient setting.

Keywords: delirium, geriatric ward, comprehensive geriatric assessment, Confusion Assessment Method, Delirium-O-Meter, Richmond Agitation-Sedation Scale

\section{Introduction}

Delirium is an acute decline in cognitive function of multifactorial etiology associated with increased risk of death, prolonged hospitalization, dementia, and admission to long-term care centers. ${ }^{1-7}$ Delirium remains a major nosocomial complication of hospitalized elderly patients that represents significant health care costs. ${ }^{8,9}$ Siddiqi et $\mathrm{al}^{10}$ reported $10 \%-31 \%$ prevalence of delirium at hospital admission, $3 \%-29 \%$ incidence of delirium during admission, and $11 \%-42 \%$ prevalence rate per hospital admission. Similar results were obtained by Ryan et $\mathrm{al}^{11}$ who diagnosed delirium in $17.6 \%-19.6 \%$ (depending on the method used) of general hospital adult inpatients, with prevalence as high as $34.8 \%$ in patients older than 80 years. Multicomponent nonpharmacological interventions may reduce delirium incidents among elderly inpatients by up to $44 \% .^{12,13}$ As expected, discontinuation of certain medication 
reduced the incidence of delirium in elderly living in longterm care facilities. ${ }^{14}$ The 2015 American Geriatrics Society (AGS) Beers Criteria recommend that elderly at high risk of delirium avoid medications such as anticholinergics, benzodiazepines, corticosteroids, H2-receptor antagonists, meperidine, and sedative hypnotics because of their potential to induce or worsen symptoms of delirium. ${ }^{15}$ Knowledge of risk factors is essential for delirium prevention: dementia; cognitive impairment; prior delirium incident; presence of functional, visual, or hearing impairment; comorbidity or severe illness; depression; prior transient cerebral ischemia or stroke; alcohol misuse; and age $\geq 75$ years are considered predisposing factors, while polypharmacy; treatment with psychoactive drugs, sedatives, or hypnotics; use of physical restraints; use of bladder catheters; presence of metabolic disorders; infections; surgeries; trauma or urgent admission; and coma are considered precipitating factors. ${ }^{5}$ However, risk factors for delirium may differ between treatment centers. Comprehensive geriatric assessment (CGA) may be useful in predicting incidents of delirium. ${ }^{16}$ We performed an observational, prospective study to analyze the factors predictive of delirium in patients admitted to the geriatric ward, including CGA results. Predictive models of delirium may be useful for identification of high-risk patients for proactive implementation of delirium preventive strategies and for determination of clinical trial eligibility. Delirium risk stratification may also be suitable for documenting estimates of hospital course and help propagate a better understanding of potential hospitalization outcomes for the patient and patient's family. ${ }^{5}$

\section{Methods}

\section{Design}

This prospective observational study was performed in the Department of Geriatrics at University Hospital No 7 SUM Uppersilesian Medical Center in Katowice, Poland, a subacute geriatric ward at a multiprofile university hospital. All reported tests were performed according to clinical indications, and no test was performed in case of refusal by the patient or care giver. No procedure exceeded beyond the scope of standard care in the ward. In 2013, a "Standard Operational Procedure for Delirium Prophylaxis" program was initiated by unit staff and approved by hospital management for use in the ward. In addition to commonly accepted delirium prophylaxis strategies, ${ }^{6,17}$ this program added Confusion Assessment Method (CAM), ${ }^{18}$ Delirium-O-Meter, ${ }^{19}$ and Richmond Agitation-Sedation $\mathrm{Scale}^{20}$ as additional delirium prevention methods. Implementation of the program was preceded by geriatrician-led staff training.

\section{Participants}

Primary analysis consisted of 788 consecutive patients aged $79.5 \pm 7.6$ years $(\bar{x} \pm \mathrm{SD})$ within a range of 60 to 100 years, among them $66 \%$ were women and $34 \%$ were men. Participants were admitted to the Department of Geriatrics at University Hospital No 7 SUM Uppersilesian Medical Center in Katowice, Poland, an acute geriatric ward at a multiprofile university hospital, between June 2013 and June 2014.

We excluded 113 patients who had been treated with antipsychotic medications because of behavioral disorders before admission and/or presented with signs of delirium on admission (five subjects). Final analysis consisted of 675 patients aged $79.2 \pm 7.7$ years $(\bar{x} \pm \mathrm{SD})$ within a range of 60 to 100 years, among them $443(66 \%)$ were women and $232(34 \%)$ were men.

\section{Measurements}

GCA was performed for all the patients, including a structured interview, physical examination, geriatric functional assessment, blood sampling, electrocardiogram (ECG), abdominal ultrasound, and chest X-ray. Mini-Mental State Examination $(\mathrm{MMSE})^{21}$ was used to assess global cognitive performance and Geriatric Depression Scale-Short Form (GDS-SF) ${ }^{22}$ to identify depression. Barthel Index of Activities of Daily Living (Barthel Index) ${ }^{23}$ and Lawton Instrumental Activities of Daily Living Scale (IADL) ${ }^{24}$ were used to determine functional status. MMSE scores range from 0 to 30, Barthel Index scores from 0 to 100, and IADL scores from 9 to 27; higher scores indicate better functional state. GDS-SF scores range from 0 to 15 with higher scores indicating higher depression probability. To assess risk of falls, a modified "Get up and Go" test ${ }^{25}$ scored from 0 to 10 was employed with lower values indicating higher risk. CAM for diagnosis of delirium ${ }^{18}$ was applied. CAM is the most widely used instrument for identification of delirium, which has been validated in high-quality studies. ${ }^{5}$ The CAM algorithm includes four criteria: acute onset and fluctuating course, inattention, disorganized thinking, and altered level of consciousness. Confirmation of the diagnosis requires the presence of both the first and the second criteria and of either the third or the fourth criterion. Delirium-O-Meter ${ }^{19}$ was used to assess delirium severity. The 12-item behavioral observation scale consists of the following categories: sustained attention, shifting attention, orientation, consciousness, apathy, hypokinesia or psychomotor retardation, incoherence, fluctuating functioning, restlessness, delusions, hallucinations, and anxiety or fear. Total scores range from 0 to 36 with higher values indicating more severe disorders. Richmond AgitationSedation $\mathrm{Scale}^{20}$ was used to assess sedation or agitation. The scale scores from +4 ("combative") to -5 ("unarousable"). 
Dementia was diagnosed according to recommendations from the National Institute on Aging-Alzheimer's Association. ${ }^{26}$ Pain intensity (PI) was assessed with the visual analog scale ${ }^{27,28}$ scored from 0 to 10 , or with Doloplus- 2 scale $^{29,30}$ based on the behavioral-observational method and scored from 0 to 30 points (with a higher score indicating more severe pain) in patients who were unable to report PI because of cognitive impairment. To harmonize both scales, for further analysis, Doloplus-2 values were divided by a factor of 3, and PI was scored from 0 to 10 in each patient. A body mass index (BMI) was calculated in all the subjects.

\section{Data collection}

Data were collected by three research nurses and entered into forms prepared for research purposes.

\section{Statistical analysis}

The obtained data were analyzed using STATISTICA version 10 (StatSoft, Inc., Tulsa, OK, USA). Chi-square test, V-square test, and Fisher's exact test were used for categorical variables and nonparametric Mann-Whitney $U$-test for quantitative variables to compare patients who developed delirium during hospitalization with those who did not. Multivariate binary logistic regression was performed to assess measures associated with delirium development. The variables were adjusted to clinical, functional, and laboratory factors. Multivariate analysis with backward elimination included variables that yielded $P$-values of 0.1 or lower in the initial univariate analysis. The Kaplan-Meier method was used to estimate probability of delirium-free hospitalization in subgroups of patients with respect to selected variables, while differences between these subgroups were assessed with the Wilcoxon-Gehan statistic. Variables were tested to define the value corresponding with the lowest $P$ level. $P$-values $<0.05$ were considered statistically significant.

\section{Ethics}

The study protocol was registered with the Bioethical Committee of the Medical University of Silesia in Katowice. In a statement, the committee wrote "the study is characterized by record review and in the context of law is not a medical experiment and does not require assessment by the bioethical committee" (Letter KNW/0022/KB/79/I/13). Based on this decision, written informed consent was not required of our study nor was separate patient consent required for our statistical analysis or research, since patient data are not disclosed outside internal hospital ward staff.

\section{Results}

Symptoms suggestive of delirium were reported, but not documented, by $2.79 \%$ of the 788 study participants before admission to the geriatric ward. Ten patients $(1.27 \%)$ died during the study period. Delirium developed in 35 out of the 675 patients $(5.2 \%)$ who had not been previously treated with neuroleptics (Figure 1). Approximately, 42.8\% of the 675 patients were treated with diuretics, $41 \%$ with

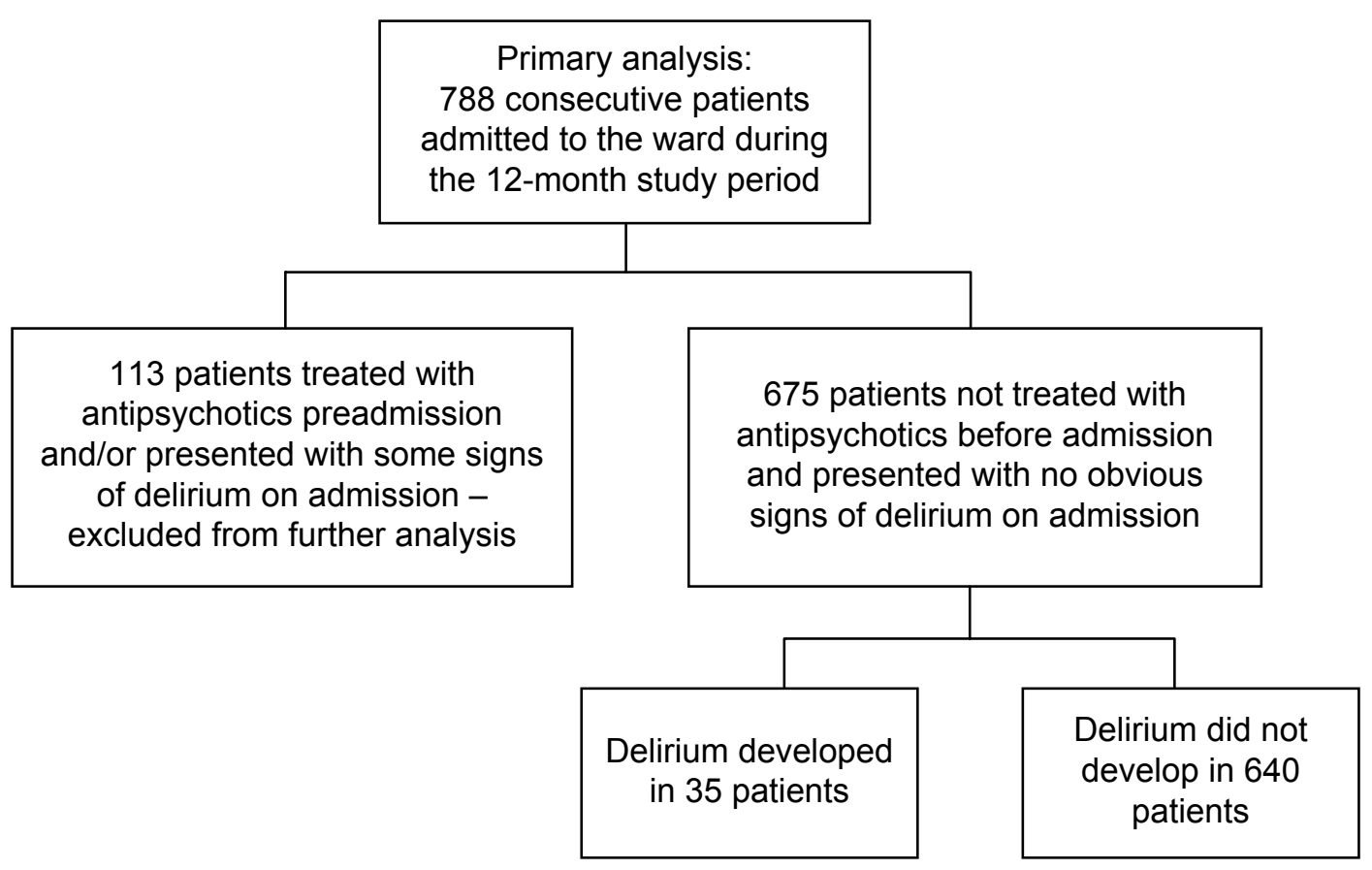

Figure I Recruitment of the study participants. 
beta blockers, 30.4\% with angiotensin converting enzyme inhibitors (ACEIs), 29.6\% with statins, 25\% with protonpump inhibitors, $23.9 \%$ with antidiabetic medications, $17.2 \%$ with aspirin, $16.6 \%$ with pain relievers, $9 \%$ with antidepressants, $8.4 \%$ with thyroxine, $5.6 \%$ with corticosteroids, and $5 \%$ with L-DOPA. Compared to the control group, patients who developed delirium were characterized by greater age and increased prevalence of dementia; congestive heart disease; peripheral artery disease; pressure ulcers; urinary incontinence; permanent or prolonged bladder catheterization; delirium and fall incidents; behavioural disorders; lower MMSE, Barthel Index, and Lawton IADL scores; higher white blood cell counts and C-reactive protein levels; lower serum total protein and albumin levels (Table 1).

Table I Demographic, clinical, and functional characteristics of the patients who developed delirium during hospitalization (group D) as compared with patients who did not (group C)

\begin{tabular}{|c|c|c|c|}
\hline \multirow[t]{2}{*}{ Variable } & $\begin{array}{l}\text { Group D } \\
n=35\end{array}$ & $\begin{array}{l}\text { Group C } \\
n=640\end{array}$ & \multirow{2}{*}{$\begin{array}{l}\text { Group } D \\
\text { vs group C } \\
P \text {-value }\end{array}$} \\
\hline & \multicolumn{2}{|c|}{ Mean \pm SD or percentage } & \\
\hline Age, years & $83.6 \pm 4.7$ & $79.0 \pm 7.7$ & $>0.001$ \\
\hline Sex, percentage of females & 74.3 & 65.2 & 0.269 \\
\hline Hypertension, \% & 68.6 & 77.8 & 0.204 \\
\hline Diabetes mellitus, \% & 22.9 & 32.2 & 0.248 \\
\hline Myocardial infarction in anamnesis, \% & 11.4 & 11.4 & 0.788 \\
\hline Congestive heart failure, $\%$ & 58.8 & 23.4 & 0.026 \\
\hline Stroke in anamnesis, \% & 16.7 & 12.2 & 0.917 \\
\hline Peripheral artery disease, $\%$ & 14.3 & 5.94 & 0.049 \\
\hline Parkinson's disease, \% & 5.71 & 5.94 & 0.754 \\
\hline Dementia, \% & 80.0 & 29.8 & $>0.001$ \\
\hline Delirium in anamnesis, \% & 8.57 & 1.72 & 0.031 \\
\hline Cancer in anamnesis, \% & $1 \mathrm{I} .4$ & 12.3 & 0.917 \\
\hline Falls in anamnesis, $\%$ & 60.0 & 34.06 & 0.002 \\
\hline Behavioral disorders in anamnesis, \% & 34.3 & 6.25 & $>0.001$ \\
\hline Pressure ulcers, \% & 14.3 & 2.03 & $>0.001$ \\
\hline Urinary incontinence, \% & 57.1 & 40.3 & 0.049 \\
\hline Bladder catheterization, \% & 28.6 & 5.94 & $>0.001$ \\
\hline Number of used medications & $5.23 \pm 2.50$ & $4.88 \pm 2.54$ & 0.445 \\
\hline Body mass index, $\mathrm{kg} / \mathrm{m}^{2}$ & $26.32 \pm 5.56$ & $28.04 \pm 7.24$ & 0.104 \\
\hline Heart rate, beats per minute & $73.80 \pm 15.56$ & $71.43 \pm 12.23$ & 0.259 \\
\hline Systolic blood pressure, $\mathrm{mmHg}$ & $134.29 \pm 25.03$ & $134.63 \pm 19.21$ & 0.299 \\
\hline Diastolic blood pressure, $\mathrm{mmHg}$ & $75.29 \pm 8.74$ & $76.77 \pm 10.06$ & 0.228 \\
\hline MMSE score & $16.80 \pm 8.38$ & $23.81 \pm 7.22$ & $>0.001$ \\
\hline Barthel Index & $49.29 \pm 30.32$ & $73.27 \pm 27.37$ & $>0.001$ \\
\hline Lawton IADL & $14.03 \pm 5.40$ & $19.26 \pm 6.19$ & $>0.001$ \\
\hline Hemoglobin, mmol/L & $7.61 \pm 1.40$ & $7.77 \pm 1.17$ & 0.491 \\
\hline White blood cells, G/L & $10.59 \pm 8.47$ & $7.54 \pm 3.36$ & 0.001 \\
\hline Total protein, $\mathrm{g} / \mathrm{L}$ & $67.1 \pm 0.77$ & $71.1 \pm 0.91$ & 0.002 \\
\hline Albumin, $g / L$ & $31.3 \pm 0.71$ & $35.4 \pm 0.61$ & $>0.001$ \\
\hline Glucose, $\mathrm{mmol} / \mathrm{L}$ & $6.02 \pm 1.82$ & $6.38 \pm 2.23$ & 0.227 \\
\hline Bilirubin, $\mu \mathrm{mol} / \mathrm{L}$ & $11.80 \pm 6.50$ & $11.29 \pm 9.23$ & 0.288 \\
\hline ALAT, nmol/L/s & $307.0 \pm 266.9$ & $342.7 \pm 382.0$ & 0.197 \\
\hline Creatinine, $\mu \mathrm{mol} / \mathrm{L}$ & $99.01 \pm 54.81$ & $92.82 \pm 58.34$ & 0.838 \\
\hline Estimated GFR using BIS_creatinine equation, $\mathrm{mL} / \mathrm{min} / \mathrm{I} .73 \mathrm{~m}^{2}$ & $57.15 \pm 21.18$ & $61.75 \pm 25.12$ & 0.434 \\
\hline Thyrotropin, $\mathrm{mlU} / \mathrm{L}$ & $2.22 \pm 3.41$ & $2.63 \pm 6.82$ & 0.733 \\
\hline Vitamin $\mathrm{BI}$, $\mathrm{pmol} / \mathrm{L}$ & $305.0 \pm 206.2$ & $314.4 \pm 201.8$ & 0.403 \\
\hline Total cholesterol, mmol/L & $4.23 \pm 1.17$ & $4.52 \pm 1.17$ & 0.480 \\
\hline LDL-cholesterol, mmol/L & $2.40 \pm 0.80$ & $2.63 \pm 0.98$ & 0.450 \\
\hline HDL-cholesterol, mmol/L & $1.29 \pm 0.52$ & $1.36 \pm 0.43$ & 0.730 \\
\hline Triglycerides, mmol/L & $1.20 \pm 0.38$ & $1.16 \pm 0.48$ & 0.344 \\
\hline C-reactive protein, $\mathrm{mg} / \mathrm{L}$ & $47.79 \pm 70.28$ & $21.40 \pm 44.63$ & 0.019 \\
\hline Sodium, $\mathrm{mmol} / \mathrm{L}$ & $139.8 \pm 5.4$ & $139.1 \pm 4.0$ & 0.743 \\
\hline Potassium, mmol/L & $4.05 \pm 0.55$ & $4.20 \pm 0.55$ & 0.228 \\
\hline Calcium, mmol/L & $2.32 \pm 0.33$ & $2.33 \pm 0.17$ & 0.019 \\
\hline
\end{tabular}

Abbreviations: ALAT, alanine transaminase; BIS, Berlin Initiative Study; GFR, glomerular filtration rate; SD, standard deviation; MMSE, Mini-Mental State Examination; IADL, Index of Instrumental Activities of Daily Living; LDL, low-density cholestorol; HDL, high-density cholestorol. 
A

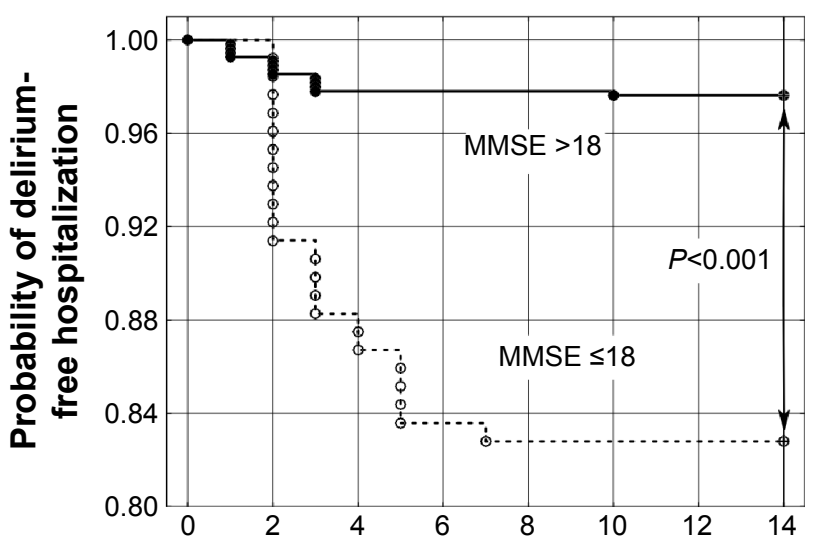

C

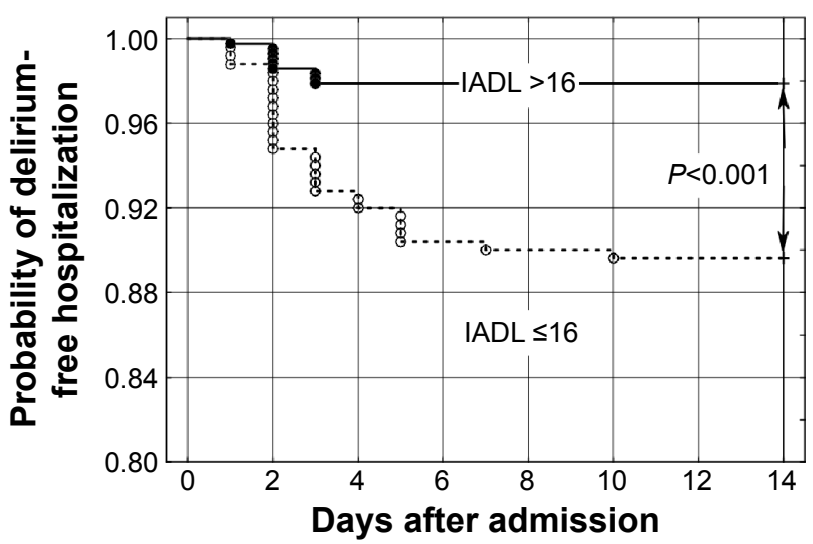

B

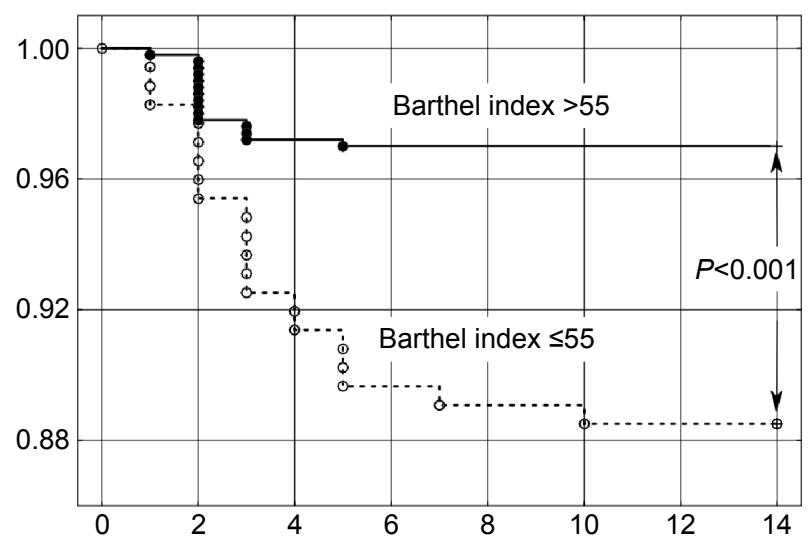

D

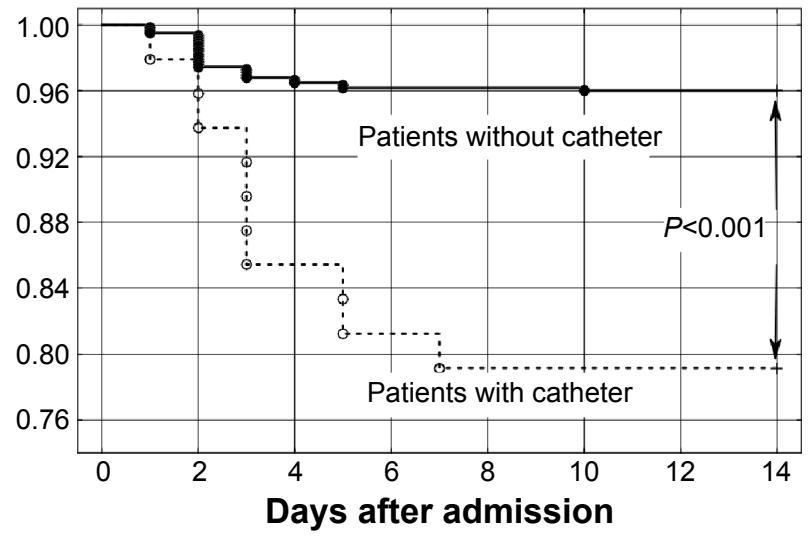

Figure 2 Probability of delirium-free hospitalization in geriatric ward patients.

Notes: Probability according to (A) Mini-Mental State Examination (MMSE) scores > 18 versus lower values, (B) Barthel Index of Activities of Daily Living (Barthel Index) $>55$ versus lower values, (C) Lawton Index of Instrumental Activities of Daily Living (Lawton IADL) $>16$ versus lower values and (D) bladder catheterization versus noncatheterization.

According to the Wilcoxon-Gehan test, individuals with MMSE scores $>18$ points had higher probability of deliriumfree hospitalization $(P<0.001)$ similar to those with Barthel Index scores $>55$ points $(P<0.001)$, Lawton IADL scores $>16$ points $(P<0.001)$, and patients without bladder catheterization $(P<0.001)$ (Figure 2$)$. Higher probability of delirium-free hospitalization was also associated with WBC count $<9.7 \mathrm{G} / \mathrm{L}(P<0.002)$, C-reactive protein serum concentration $<33 \mathrm{mg} / \mathrm{L}(P<0.001)$, serum total protein concentration $>64 \mathrm{~g} / \mathrm{L}(P<0.001)$, and albumin concentration $>30 \mathrm{~g} / \mathrm{L}(P<0.001)$ (Figure 3$)$. Multivariate logistic regression analysis included eleven quantitative variables and 30 categorical variables that yielded $P$-values of 0.1 or lower in the initial univariate analysis. Five factors associated with the development of inpatient delirium were included in the final multivariate logistic regression analysis: transfer between hospital wards (odds ratio $[\mathrm{OR}]=2.78$; confidence interval $[\mathrm{CI}]=1.54-5.01 ; P=0.001)$, preexisting dementia $(\mathrm{OR}=2.29 ; \mathrm{CI}=1.44-3.65 ; P<0.001)$, previous delirium incidents $(\mathrm{OR}=2.23 ; \mathrm{CI}=1.47-3.38 ; P<0.001)$, previous fall incidents $(\mathrm{OR}=1.76 ; \mathrm{CI}=1.17-2.64 ; P=0.006)$, and use of proton-pump inhibitors $(\mathrm{OR}=1.67$; $\mathrm{CI}=1.11-2.53$; $P=0.014)$.

\section{Discussion}

Development of delirium is a major nosocomial complication of the hospitalized elderly patients. ${ }^{7,31}$ Prevention of this condition is a major priority for hospitalized elderly patients. ${ }^{32}$ Predictive models of inpatient delirium incidents may be useful for geriatric admission guidelines. Unfortunately, the pathophysiology of delirium is poorly understood and this disorder is frequently unrecognized or overlooked. ${ }^{5}$ Delirium is often characterized by fluctuating psychological symptom progression that is difficult to assess subjectively. Complicating assessment further, various subtypes of delirium ${ }^{33,34}$ have been defined. Preexisting dementia is the leading risk factor for development of delirium in geriatric inpatients, and distinguishing between these in the clinical setting may be 
A
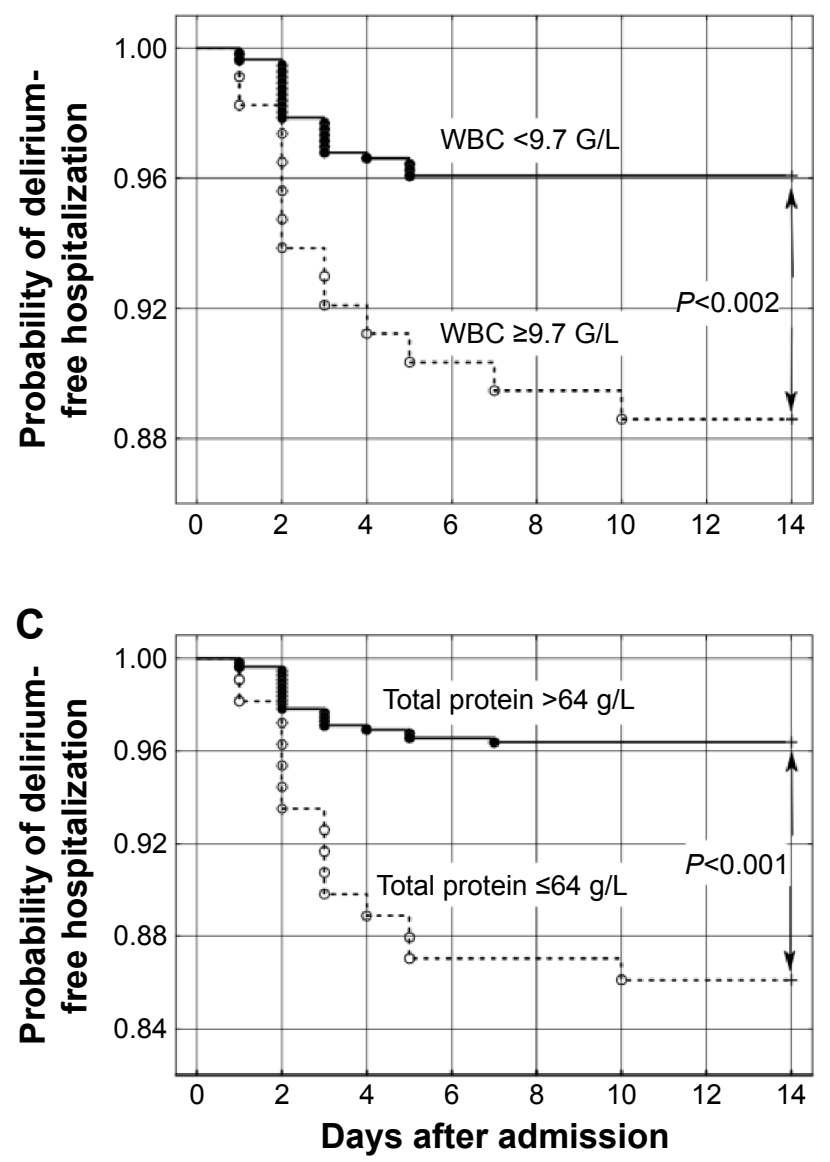

B

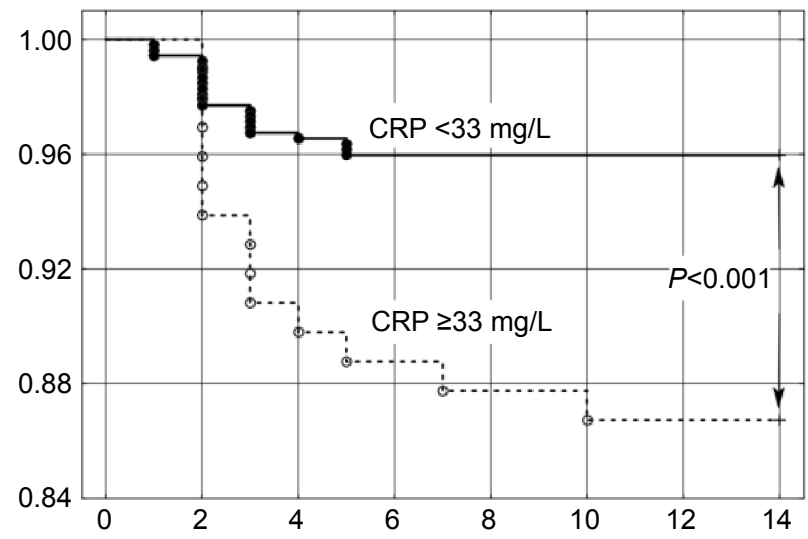

D

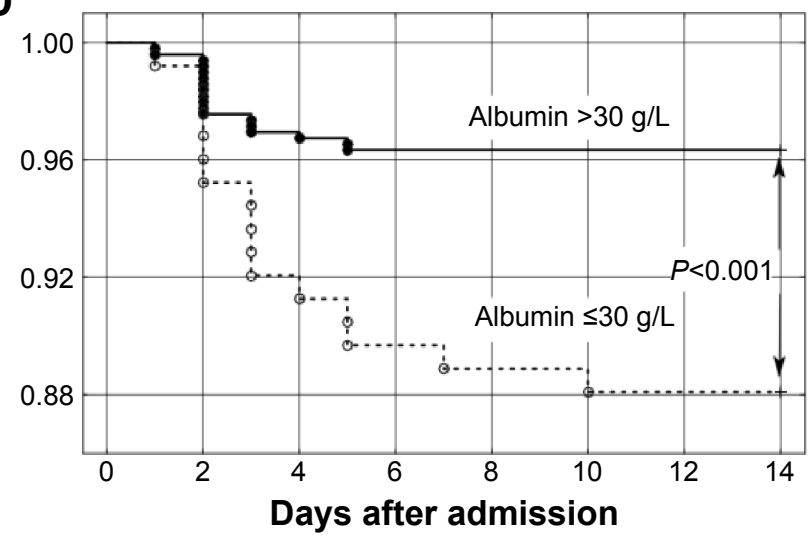

Figure 3 Probability of delirium-free hospitalization in geriatric ward patients according to WBC, CRP, and total serum protein and serum albumin levels. Notes: $(\mathbf{A})$ White blood cells $(\mathrm{WBC})<9.7 \mathrm{G} / \mathrm{L}$ versus higher values, $(\mathbf{B}) \mathrm{C}$-reactive protein $(\mathrm{CRP})<33 \mathrm{mg} / \mathrm{L}$ versus higher values, $(\mathbf{C})$ total serum protein level $>64 \mathrm{~g} / \mathrm{L}$ versus lower values, and (D) serum albumin level $>30 \mathrm{~g} / \mathrm{L}$ versus lower values.

difficult, even for experienced clinicians. ${ }^{35}$ Numerous factors may affect delirium, among them are psychoactive agents, especially antipsychotic medications used to treat behavioral and psychological disorders associated with psychogeriatric syndromes. ${ }^{36-39}$ None of the 788 study participants had documented delirium incidents before admission to the geriatric ward. However, 113 patients were undergoing treatment with antipsychotic medication, and it is likely that a portion of these patients were receiving treatment for delirium. Since antipsychotics may hinder the recognition of delirium, we excluded patients treated with antipsychotic medications ( $14.3 \%$ of all patients admitted to the ward during the observation period). Consequently, the number of patients who developed delirium during hospitalization may not reflect the total incidence of this syndrome. Prevalence of delirium at admission to the geriatric ward was assessed in other studies at $12 \%,{ }^{40} 18.5 \%,{ }^{16}$ and $25 \%,{ }^{41}$ while incidence during hospitalization was $6.6 \%,{ }^{42} 11.8 \%,{ }^{16}$ and $13.3 \% .{ }^{43}$ Similarly, we identified multiple factors associated with increased risk of the development of delirium, some of which have not been previously reported: greater age, dementia, congestive heart disease, peripheral artery disease, pressure ulcers, urinary incontinence, permanent or prolonged bladder catheterization, history of delirium episodes, behavioral disorders, history of falls, functional dependence, increased markers of inflammation, and decreased serum total protein and albumin level. Multivariate logistic regression analysis allowed identification of factors predictive of inpatient delirium development, specific for the geriatric ward. Multivariate logistic regression model consisted of five independent variables in relation to the risk of development of delirium: transfer between hospital wards, preexisting diagnosis of dementia, previous delirium incidents, previous fall incidents, and use of proton-pump inhibitors.

It may be assumed that patient transfers from other hospital wards are associated with delirium risk factors such as poor general health, increased prevalence of major geriatric syndromes, subsequent change of surroundings, and prolonged hospitalization. ${ }^{7,31}$ Dementia, previous delirium, and fall incidents are well-recognized factors associated 
with delirium. ${ }^{1}$ A pathophysiologic mechanism for the association between proton-pump inhibitors (PPIs) and development of delirium remains elusive. PPIs are used frequently in the geriatric inpatient setting, often for prolonged periods of time and are not necessarily taken according to indications. ${ }^{44}$ Increasing evidence suggests that PPIs may trigger potentially serious complications. ${ }^{45}$ Some case reports suggest that omeprazole may induce delirium. ${ }^{46,47}$ Use of PPIs was associated with increased mortality adjusted for age, sex, comorbidity, delirium, and use of aspirin and SSRIs in patients of acute geriatric wards and nursing homes. ${ }^{48} \mathrm{In}$ elderly patients discharged from acute care medical wards, high-dose PPI therapy is associated with increased 1-year mortality. ${ }^{49}$ Most of our study group patients treated with PPIs prior to admission had used these drugs for unspecified periods of time. Treatment was continued at the ward until indications for further treatment or treatment cessation could be determined. The 2015 AGS Beers Criteria recommend the avoidance of PPI therapy beyond 8 weeks without justification due to the increased risk of Clostridium difficile infection, bone loss, and fractures. ${ }^{15} \mathrm{We}$ observed that proton-pump inhibitors may increase the risk of delirium in hospitalized geriatric unit patients. However, we were unable to determine the mechanism behind the PPI and geriatric mortality association. Prolonged use of PPIs is associated with increased risk of infections (C. difficile, ${ }^{50}$ salmonellosis, ${ }^{51}$ community-acquired pneumonia ${ }^{52}$ ), vitamin B12 deficiency, ${ }^{53,54}$ and hypomagnesemia. ${ }^{45,55}$ Infection is a recognized precipitating factor for delirium. ${ }^{5}$ Delirium-free hospitalization probability was diminished in patients with increased inflammatory markers (Figure 3). Poor vitamin B12 status increases risk of cognitive decline. ${ }^{56}$ Some observations suggest that hypomagnesemia may be a factor precipitating delirium..$^{57,58}$ PPIs, especially omeprazole, affect pharmacokinetics of other drugs, among them benzodiazepines and antidepessants, ${ }^{59}$ increasing risk of adverse effects. PPIs can cross the blood-brain barrier and block the vacuolar-type ATPase proton pumps leading to decreased degradation of amyloid beta. ${ }^{60,61}$ A recent study by Akter et $\mathrm{al}^{62}$ indicates that even a short course of PPIs may impair cognitive functions in young healthy volunteers. The concept of microbiome gut-brain axis is also intriguing. ${ }^{63}$ PPIs significantly influence enteric microbiota, ${ }^{64,65}$ and there exists increasing evidence that gut-microbiota signaling to brain by means of neural, endocrine, immune, and humoral links may influence brain function. ${ }^{66}$ Some observations suggest possible association between gut-microbiota and anxiety or depressive syndromes. ${ }^{67,68}$ Thus, the pathophysiology of the relationship between PPI therapy and the risk of delirium may be complex. We were unable to confirm the observation of Goldberg et $\mathrm{al}^{31}$ that an increased number of room transfers was associated with increased incidence of delirium.

\section{Conclusion}

Transfer between hospital wards, preexisting dementia, previous delirium incidents, previous fall incidents, and use of proton-pump inhibitors are predictive of delirium incidents in the geriatric inpatient setting.

\section{Acknowledgments}

This project was funded by Medical University of Silesia grants to statutory work (contracts KNW-1-059/K/3/0 and KNW-1-029/K/4/0) and graduate student research agreement (KNW-2-011/D/5/K). The funding body played no role in the formulation of the design, methods, subject recruitment, data collection, analysis, or preparation of this paper.

\section{Author contributions}

IO and JS contributed to the study conception and design, evaluation of the subjects, data collection, analysis and interpretation of data, and drafting of article. KW performed analysis and interpretation of data, drafting of article, and revising of drafts. All authors approved the final paper. All authors contributed toward data analysis, drafting and critically revising the paper and agree to be accountable for all aspects of the work.

\section{Disclosure}

The authors report no conflicts of interest in this work.

\section{References}

1. Jitapunkul S, Pillay I, Ebrahim S. Delirium in newly admitted elderly patients: a prospective study. Q J Med. 1992;83:307-314.

2. Witlox J, Eurelings LS, de Jonghe JF, et al. Delirium in elderly patients and the risk of postdischarge mortality, institutionalization, and dementia: a meta-analysis. JAMA. 2010;304:443-451.

3. Han JH, Eden S, Shintani A, et al. Delirium in older emergency department patients is an independent predictor of hospital length of stay. Acad Emerg Med. 2011;18:451-457.

4. Fick DM, Steis MR, Waller JL, Inouve SK. Delirium superimposed on dementia is associated with prolonged length of stay and poor outcomes in hospitalized older adults. J Hosp Med. 2013;8:500-505.

5. Inouye SK, Westendorp RGJ, Saczynski JS. Delirium in elderly people. Lancet. 2014;383:911-922.

6. Flaherty JH. Delirium. In: Sinclair AJ, Morley JE, Vellas B, editors. Pathy's Principles and Practive of Geriatric Medicine. Vol 2. 5th ed. Chichester, UK: Willey-Blackwell; 2012;844-846.

7. Noriega FJ, Vidán MT, Sánchez E, et al. Incidence and impact of delirium on clinical and functional outcomes in older patients hospitalized for acute cardiac diseases. Am Heart J. 2015;170:938-944.

8. Leslie E, Cerin E. Are perceptions of the local environment related to neighbourhood satisfaction and mental health in adults? Prev Med. 2008;47:273-278.

9. Bail K, Goss J, Draper B, et al. The cost of hospital-acquired complications for older people with and without dementia; a retrospective cohort study. BMC Health Serv Res. 2015;15:91. 
10. Siddiqi N, House AO, Holmes JD. Occurrence and outcome of delirium in medical in-patients: a systematic literature review. Age Ageing. 2006; 35:350-364.

11. Ryan DJ, O’Regan NA, Caoimh RÓ, et al. Delirium in an adult acute hospital population: predictors, prevalence and detection. BMJ Open. 2013;3:pii: e001772.

12. Martinez F, Tobar C, Hill N. Preventing delirium: should nonpharmacological, multicomponent interventions be used? A systematic review and meta-analysis of the literature. Age Ageing. 2015;44: 196-204.

13. Hshieh TT, Yue J, Oh E, et al. Effectiveness of multicomponent nonpharmacological delirium interventions: a meta-analysis. JAMA Intern Med. 2015;175:512-520.

14. Clegg A, Siddiqi N, Heaven A, Young J, Holt R. Interventions for preventing delirium in older people in institutional long-term care. Coch Dat Syst Rev. 2014;1:CD009537.

15. American Geriatrics Society 2015 Beers Criteria Update Expert Panel. American Geriatrics Society 2015 Updated Beers Criteria for Potentially Inappropriate Medication Use in Older Adults. J Am Geriatr Soc. 2015; 63:2227-2246.

16. Avelino-Silva TJ, Farfel JM, Curiati JA, et al. Comprehensive geriatric assessment predicts mortality and adverse outcomes in hospitalized older adults. BMC Geriatr. 2014;14:129.

17. Inouye SK, Bogardus ST Jr, Charpentier PA, et al. A multicomponent intervention to prevent delirium in hospitalized older patients. $N$ Engl J Med. 1999;340:669-676.

18. Inouye $\mathrm{SK}$, van Dyck $\mathrm{CH}$, Alessi CA, et al. Clarifying confusion: the confusion assessment method. A new method for detection of delirium. Ann Intern Med. 1990;113:941-948.

19. de Jonghe JF, Kalisvaart KJ, Timmers JF, Kat MG, Jackson JC. DeliriumO-Meter: a nurses' rating scale for monitoring delirium severity in geriatric patients. Int J Geriatr Psychiatry. 2005;20:1158-1166.

20. Sessler CN, Gosnell MS, Grap MJ, et al. The Richmond AgitationSedation Scale: validity and reliability in adult intensive care unit patients. Am J Respir Crit Care Med. 2002;166:1338-1344.

21. Folstein MF, Folstein SE, McHugh PR. Mini-Mental State: a practical method for grading the cognitive state of patients for the clinician. J Psychiatr Res. 1975;12:189-198.

22. Sheikh JI, Yesavage JA. Geriatric Depression Scale (GDS): recent evidence and development of a shorter version. Clin Gerontol. 1986;5: $165-173$.

23. Mahoney FI, Barthel DW. Functional evaluation: the Barthel Index. Maryland State Med J. 1965;14:56-61.

24. Lawton MP, Brody EM. Assessment of older people: self-maintaining and instrumental activities of daily living. Gerontol. 1969;9:179-186.

25. Mathias S, Nayak US, Isaacs B. Balance in elderly patients: the "get-up and go" test. Arch Phys Med Rehabil. 1986;67:387-389.

26. McKhann GM, Knopman DS, Chertkow H, et al. The diagnosis of dementia due to Alzheimer's disease: recommendations from the National Institute on Aging-Alzheimer's Association workgroups on diagnostic guidelines for Alzheimer's disease. Alzheimers Dement. 2011;7: 263-269.

27. Joyce CR, Zutshi DW, Hrubes V, et al. Comparison of fixed interval and visual analogue scales for rating chronic pain. Eur J Clin Pharmacol. 1975;8:415-420.

28. Hjermstad MJ, Fayers PM, Haugen DF, et al. Studies comparing Numerical Rating Scales, Verbal Rating Scales, and Visual Analogue Scales for assessment of pain intensity in adults: a systematic literature review. J Pain Symptom Manage. 2011;41:1073-1093.

29. Wary B. Doloplus-2, a scale for pain measurement. Soins Gerontol. 2011;19:25-27.

30. Lefebvre-Chapiro S. The Doloplus-2 scale - evaluating pain in the elderly. Eur J Palliat Care. 2001;8:191-194.

31. Goldberg A, Straus SE, Hamid JS, et al. Room transfers and the risk of delirium incidence amongst hospitalized elderly medical patients: a case-control study. BMC Geriatr. 2015;15:70-78.
32. Yue J, Tabloski P, Dowal SL, et al. NICE to HELP: operationalizing National Institute for Health and Clinical Excellence guidelines to improve clinical practice. J Am Geriatr Soc. 2014;62:754-761.

33. Leonard MM, Agar M, Spiller JA, et al. Delirium diagnostic and classification challenges in palliative care: subsyndromal delirium, comorbid delirium-dementia, and psychomotor subtypes. J Pain Symptom Manage. 2014;48:199-214.

34. Kim SY, Kim SW, Kim JM, et al. Differential associations between delirium and mortality according to delirium subtype and age: a prospective cohort study. Psychosom Med. 2015;77:903-910.

35. Fong TG, Davis D, Growdon ME, et al. The interface between delirium and dementia in elderly adults. Lancet Neurol. 2015;14:823-832.

36. Davies EA, O’Mahony MS. Adverse drug reactions in special populations - the elderly. Br J Clin Pharmacol. 2015;80:796-807.

37. Kishi T, Hirota T, Matsunaga S, et al. Antipsychotic medications for the treatment of delirium: a systematic review and meta-analysis of randomised controlled trials. J Neurol Neurosurg Psychiatry. 2015. Epub 2015 Sep 4. doi:/jnnp-2015-311049.

38. Koponen M, Tolppanen AM, Taipale H, et al. Incidence of antipsychotic use in relation to diagnosis of Alzheimer's disease among communitydwelling persons. Br J Psychiatry. 2015;207:444-449.

39. Nørgaard A, Jensen-Dahm C, Gasse C, et al. Time trends in antipsychotic drug use in patients with dementia: a nationwide study. J Alzheimers Dis. 2015;49:211-220.

40. Bellelli G, Morandi A, Davis DH, et al. Validation of the 4AT, a new instrument for rapid delirium screening: a study in 234 hospitalised older people. Age Ageing. 2014;43:496-502.

41. Hein C, Forgues A, Piau A, et al. Impact of polypharmacy on occurrence of delirium in elderly emergency patients. J Am Med Dir Assoc. 2014;15:e11-e15.

42. Bo M, Martini B, Ruatta C, et al. Geriatric ward hospitalization reduced incidence delirium among older medical inpatients. Am J Geriatr Psychiatry. 2009; 17:760-768.

43. Holt R, Young J, Heseltine D. Effectiveness of a multi-component intervention to reduce delirium incidence in elderly care wards. Age Ageing. 2013;42:721-727.

44. Ksiądzyna D, Szeląg A, Paradowski L. Overuse of proton pump inhibitors. Pol Arch Med Wewn. 2015;125:289-298.

45. Corleto VD, Festa S, Di Giulio E, et al. Proton pump inhibitor therapy and potential long-term harm. Curr Opin Endocrinol Diabetes Obes. 2014;21:3-8.

46. Fireman Z, Kopelman Y, Sternberg A. Central nervous system side effects after proton pump inhibitor treatment. J Clin Gastroenterol. 1997; 25:718.

47. Heckmann JG, Birklein F, Neundörfer B. Omeprazole-induced delirium. J Neurol. 2000;247:56-57.

48. Teramura-Grönblad M, Bell JS, Pöysti MM, et al. Risk of death associated with use of PPIs in three cohorts of institutionalized older people in Finland. J Am Med Dir Assoc. 2012;5:9-13.

49. Maggio M, Corsonello A, Ceda GP, et al. Proton pump inhibitors and risk of 1-year mortality and rehospitalization in older patients discharged from acute care hospitals. JAMA Intern Med. 2013;173:518-523.

50. Kurti Z, Lovasz BD, Mandel MD, et al. Burden of Clostridium difficile infection between 2010 and 2013: trends and outcomes from an academic center in Eastern Europe. World J Gastroenterol. 2015;21:6728-6735.

51. Freeman R, Dabrera G, Lane C, et al. Association between use of proton pump inhibitors and non-typhoidal salmonellosis identified following investigation into an outbreak of Salmonella Mikawasima in the UK, 2013. Epidemiol Infect. 2015;1:1-8.

52. Lambert AA, Lam JO, Paik JJ, et al. Risk of community-acquired pneumonia with outpatient proton-pump inhibitor therapy: a systematic review and meta-analysis. PLoS One. 2015;10:e0128004. doi:10.1371/ journal.pone.0128004.

53. Ruscin JM, Page RL 2nd, Valuck RJ. Vitamin B(12) deficiency associated with histamine(2)-receptor antagonists and a proton-pump inhibitor. Ann Pharmacother. 2002;36:812-816. 
54. Lam JR, Schneider JL, Zhao W, et al. Proton pump inhibitor and histamine 2 receptor antagonist use and vitamin B12 deficiency. JAMA. 2013;310:2435-2442.

55. Kieboom BC, Kiefte-de Jong JC, Eijgelsheim M, et al. Proton pump inhibitors and hypomagnesemia in the general population: a populationbased cohort study. Am J Kidney Dis. 2015;66:775-782.

56. O’Leary F, Allman-Farinelli M, Samman S. Vitamin $B_{12}$ status, cognitive decline and dementia: a systematic review of prospective cohort studies. Br J Nutr. 2012;108:1948-1961.

57. Caplan JP, Chang G. Refeeding syndrome as an iatrogenic cause of delirium: a retrospective pilot study. Psychosomatics. 2010;51:419-424.

58. Sgarlata C, Rollone M, Ricevuti G, et al. A case of delirium due to severe hypomagnesemia occurred during long-term PPIs treatment. Eur Geriatr Med. 2013;4(Suppl 1):S137.

59. Wedemeyer RS, Blume H. Pharmacokinetic drug interaction profiles of proton pump inhibitors: an update. Drug Saf. 2014;37:201-211.

60. Majumdar A, Capetillo-Zarate E, Cruz D, et al. Degradation of Alzheimer's amyloid fibrils by microglia requires delivery of $\mathrm{ClC}-7$ to lysosomes. Mol Biol Cell. 2011;22:1664-1676.

61. Badiola N, Alcalde V, Pujol A, et al. The proton-pump inhibitor lansoprazole enhances amyloid beta production. PLoS One. 2013;8:e58837. doi:10.1371/journal.pone.0058837.
62. Akter S, Hassan MR, Shahriar M, et al. Cognitive impact after shortterm exposure to different proton pump inhibitors: assessment using CANTAB software. Alzheimers Res Ther. 2015;7:79.

63. Sherwin E, Rea K, Dinan TG, et al. A gut (microbiome) feeling about the brain. Curr Opin Gastroenterol. Epub 2016 Jan 12.

64. Freedberg DE, Toussaint NC, Chen SP, et al. Proton pump inhibitors alter specific taxa in the human gastrointestinal microbiome: a crossover trial. Gastroenterol. 2015;149:883-885.

65. Imhann F, Bonder MJ, Vich Vila A, et al. Proton pump inhibitors affect the gut microbiome. Gut. Epub 2015 Dec 9. doi:10.1136/gutjnl-2015310376 .

66. Carabotti M, Scirocco A, Maselli MA, Severi C. The gut-brain axis: interactions between enteric microbiota, central and enteric nervous systems. Ann Gastroenterol. 2015;28:203-209.

67. Foster JA, McVey Neufeld KA. Gut-brain axis: how the microbiome influences anxiety and depression. Trends Neurosci. 2013;36: 305-312.

68. Naseribafrouei A, Hestad K, Avershina E, et al. Correlation between the human fecal microbiota and depression. Neurogastroenterol Motil. 2014;26:1155-1162.
Clinical Interventions in Aging

\section{Publish your work in this journal}

Clinical Interventions in Aging is an international, peer-reviewed journal focusing on evidence-based reports on the value or lack thereof of treatments intended to prevent or delay the onset of maladaptive correlates of aging in human beings. This journal is indexed on PubMed Central, MedLine,

\section{Dovepress}

CAS, Scopus and the Elsevier Bibliographic databases. The manuscript management system is completely online and includes a very quick and fair peer-review system, which is all easy to use. Visit http://www.dovepress. com/testimonials.php to read real quotes from published authors. 